\title{
ANÁLISE DA GESTÃO DE ESTOQUES EM UM ELO DA CADEIA DE SUPRIMENTOS COM FOCO NAS DIRETRIZES DO LEAN OFFICE
}

Marcus Vinicius Dantas de Assunção marcus.assuncao@ifrn.edu.br, Jessica Merhy Carlos Monteiro jessicamerhy@hotmail.com, Camila Monteiro Guilherme camilam.guilherme@hotmail.com, Karolayne Nayanne Martins Oliveira oliveirakarolayne16@gmail.com, Fernanda Barreto de Almeida Rocha Mariz , fernanda.barreto@ifrn.edu.br

\section{RESUMO}

O presente artigo aborda os conceitos do Lean Office aplicados a um elo da cadeia de suprimentos do ramo de venda de livros, com o foco na gestão de estoques. Dessa forma, coletou-se os principais conceitos apontados na literatura para elaborar um roteiro, o qual foi aplicado tanto no Centro de Distribuição, quanto na Livraria. Gerando como produto uma exposição de como é tratada a gestão estoques em tais organizações e se há preocupação, por parte dos colaboradores, em se adotar os conceitos Lean. Posto isso, foi traçado o panorama dos impactos que uma gestão de estoques integradas tem na geração de lucros para as empresas. Assim, como produto desse estudo, foi possível concluir que as empresas analisadas desconhecem os possíveis benefícios que a ferramenta Lean Office poderia Ihes trazer.

PALAVRAS-CHAVE: Lean Office, Gestão de estoques, Cadeia de suprimentos.

\section{ANALYSIS OF STOCK MANAGEMENT IN A SUPPLY CHAIN FOCUS WITH FOCUS ON LEAN OFFICE GUIDELINES}

\begin{abstract}
This article addresses the concepts of Lean Office applied to a supply chain link in the book retail business, with a focus on inventory management. Thus, we collected the main concepts pointed out in the literature to elaborate a script, which was applied both in the Distribution Center and in the Bookstore. Generating as a product an exposition of how it is treated the stock management in such organizations and if there is concern on the part of the collaborators in adopting the concepts Lean. With this in mind, the panorama of the impacts that an integrated inventory management has on the
\end{abstract}


generation of profits for the companies was traced. Thus, as a product of this study, it was possible to conclude that the companies analyzed do not know the possible benefits that the Lean Office tool could bring them.

KEYWORDS: Lean Office, Inventore Management, Supply Chain.

\section{INTRODUÇÃO}

A gestão de estoques pode ser um fator decisivo na competitividade e na relação entre organizações participantes de uma cadeia de suprimentos, haja vista essa representar até $65 \%$ dos custos logísticos associados de uma empresa (BALLOU, 2006). Seja qual for a mudança na gestão, isso pode gerar impactos que refletem em toda a cadeia. Sendo assim, faz-se necessário uma comunicação eficaz entre os elos dessa cadeia o que favorece o controle integrado desejado.

Desse modo, para que esse controle funcione, além da integração da comunicação entre as empresas, é necessário que se utilizem meios de previsão para os produtos estocados; coordenação nos custos e gastos necessários; e que as organizações contem com métodos de previsões de demanda quantitativos e qualitativos, de modo organizado e sustentável. A função administrativa caminha a passos largos para uma conduta mais alinhada à redução de gasto, tornando seus processos cada vez mais enxutos.

A produção enxuta, originada nas indústrias automobilísticas com o surgimento do Sistema Toyota de Produção, possui como objetivo alcançar o menor desperdício possível. Não obstante, o Lean Office aplica tais conceitos, da gestão enxuta, nos ambientes administrativos, possibilitando um maior aproveitamento de tempo, produtividade dos colaboradores e capital. Com isso, os fluxos de valor identificados estão atrelados às informações e conhecimento.

A partir do exposto, este artigo visa analisar a gestão de estoques em um elo de uma cadeia de suprimentos com foco no Lean Office, em um Centro de Distribuição (CD) de livros e uma livraria. Para, assim, comparar o que, dos conceitos apontados na teoria, está sendo posto em prática.

\section{REFERENCIAL TEÓRICO}

\subsection{Gestão da Cadeia de Suprimentos}

O gerenciamento da cadeia de suprimentos é a coordenação dos fluxos das atividades logísticas, de modo eficiente, ao longo dos processos, sem deixar lacunas entre os elos. Melo; Nickel; Saldanhada-Gama (2009) afirmam essa gestão se baseia em coordenar diferentes movimentações (bens, serviços, finanças e informações) ao longo de um processo, englobando todos procedimentos e relações existentes em uma operação, visando apoiar e/ou alcançar esses objetivos.

Para que essa cadeia cumpra com as necessidades exigidas em cada nível e também possa existir um bom desempenho, é essencial que se tenha uma relação eficiente entre esses elos, de modo 
que nenhum deles se rompa, pois, caso contrário, isso poderá fazer com que a cadeia seja afetada, piorando o seu desenvolvimento e podendo trazer também prejuízos a empresa. Ao contrário do que muitos pensam, o que acontece na parte interna da empresa também integra a cadeia de suprimentos, no caso as suas funções internas também fazem parte de todo o processo externo que permeia a cadeia, que tem objetivo maior satisfazer o cliente de acordo com suas necessidades e gerar lucro para a empresa (COOPER; LAMBERT; PAGH, 1997).

O processo de distribuição é considerado um dos mais importantes da cadeia de suprimentos, uma vez que envolve as operações desde o produto acabado no estoque até o consumidor final (LOURENZAN; SILVA, 2004), com o objetivo de ampliar a margem de vendas.

Segundo Lummus; Voturka (1999), só começou a existir uma preocupação para concretizar esse objetivos a partir dos anos 90 , basicamente por três principais motivos: as empresas buscam cada vez mais focar no seu papel, com isso buscam fornecedores que the deem qualidade e baixo custo; a crescente competitividade, deixando de ser apenas local e se tornando também internacional; a compreensão de que não é somente um elo da cadeia que irá tornar melhor o seu desempenho mercado e sim o conjunto de elos trabalhados de maneira eficiente.

Os termos lean e agile, adaptados à cadeia, mostram-se fundamentais, tornando-a mais enxuta e ágil, livre de uma maior quantidade de desperdícios. Esse modelo enxuto da produção adota a filosofia básica de "produzir mais por menos" corroborando com os conceitos de Pires (2004) que ainda acrescenta que remover anomalias e atividades que podem causar desperdícios ao longo do processo é um dos focos dessa produção.

\subsection{Gestão de Estoques}

A gestão de estoques é o gerenciamento de materiais que estão dentro da organização e ainda não foram vendidos ou utilizados, que são considerados desde a sua previsão até o momento de expedir o material para a venda. É uma agregação acumulada de recursos materiais em um sistema de transformação, tendo como objetivo a busca por o mínimo custo possível (SLACK; CHAMBERS; JOHNSTON, 2009).

Essa gestão eficiente e eficaz é vista como uma vantagem competitiva em relação às demais empresas quando administrada de maneira eficiente podendo trazer vantagens, como, por exemplo, um bom nível de serviço e proteção contra eventualidades e aumento de preços.

Dentre diversos tipos de estoques, os produtos acabados são os materiais que permanecem no estabelecimento ou no armazém aguardando a sua venda, tanto em empresas varejistas quanto centros de distribuições; o estoque em trânsito que se refere ao tempo na qual a mercadoria permanece nos veículos de transporte durante a entrega (BALLOU, 2006); o inativo, são aqueles produtos que não obtiveram giro e tornaram-se obsoletos; estoque de proteção tem como objetivo proteger a empresa de eventualidades no mercado que causam instabilidade no estoque; e o estoque sazonal serve para períodos de grande demanda, ou períodos de pico, para nivelar os pedidos e demanda.

Os diversos tipos de estoque possuem alguns princípios fundamentais para o seu gerenciamento. Conforme afirma Viana (2000), esses princípios consistem essencialmente na busca pelo equilíbrio 
entre estoque e consumo, o que será alcançado mediante algumas funções, regras e critérios: impedir a entrada de materiais desnecessários; centralizar as informações para que se tenha um melhor acompanhamento e planejamento; definir medidas para cada tipo de material; determinar o número de itens para a permanência no estoque; analisar e acompanhar a evolução do estoque na empresa; desenvolver e implantar uma padronização de materiais; acionar o setor de compras; decidir sobre a regularização de materiais; realizar inventários periódicos para que materiais obsoletos e dispensáveis sejam retirados do estoque.

Para executar esses princípios e até iniciar o gerenciamento do estoque é necessário método de previsão para determinar o tempo e quantidade dos produtos, algumas dessas maneiras se dão pelos métodos da média móvel, móvel ponderada e do último período. Após esse meio de previsão e planejamento ocorre a etapa do controle, cuja função é produzir os inventários e classificar os itens por meio da curva $A B C$, desde que seja utilizada nesse ponto para calcular e identificar grupos que cada produto pertence. De acordo com essa classificação alguns autores tratam que algumas vezes chamada de $80 / 20$, essa análise direciona os resultados para a situação em que $80 \%$ do valor do estoque são responsáveis por apenas $20 \%$ de todos os itens estocados (SLACK; CHAMBERS; JOHNSTON, 2009), e o conceito 80-20 é formado a partir do momento em que a parte maior das vendas é gerada por um conjunto de relativamente poucos produtos das respectivas linhas e a partir do método conhecido como a Lei de Pareto (BALLOU, 2006).

Em síntese, para uma empresa atuar com sucesso no mercado de trabalho sua administração central define uma política de estoques no qual será estabelecido princípios para o seu planejamento, envolvendo assim área industrial, comercial e financeira com o um estoque mínimo, para cada classificação de produto (A, B e C), bem como a aplicação de uma auditoria nos estoques (FERREIRA et al., 2015).

\subsection{Lean Office}

Os primeiros conceitos de produção enxuta se iniciaram nas indústrias automobilísticas com o nascimento do Sistema Toyota de Produção (STP), o qual possui como preceito básico a busca por alcançar o mínimo de desperdício possível. Womack; Jones (2004) destacam que o Lean é uma forma de definir valor para que os processos não sofram interrupções desnecessárias.

O Lean Office é uma ferramenta, cujo objetivo é implantar princípios já utilizados nas produções enxutas na esfera administrativa (CARNEIRO et al., 2017). Como, por exemplo, mapear e evitar desperdícios e tornar o fluxo dos processos mais claros. Diminuindo desperdícios como papeladas excessivas; processos os quais não agregam valor as informações e dados; improdutividade por parte dos colaboradores, etc.

No que se refere ao Lean Office, os fluxos de valor estão atrelados às informações e conhecimento, os quais são tão importantes quanto os fluxos de materiais em uma manufatura e, como destaca McManus (2003), pode passar pelos mesmos problemas relacionados a desperdícios, como: espera, estoque, transporte, superprocessamento, movimentação desnecessária, superprodução e defeitos.

Como destaca Lareau (2002), os desperdícios administrativos podem ser definidos, podendo-se 


\section{ISSN - 2447-178X}

destacar as seguintes classificações:

- Agenda: utilização inadequada do tempo.

- Alinhamento de objetivos: esforço, desnecessário, gasto trabalhando e corrigindo objetivos mal compreendidos pelo funcionário;

- Checagens desnecessárias: trabalho desperdiçado em inspeções e retrabalhos;

- Desperdício de Processamento: trabalho executado de forma inadequada;

- Domínio: ocorre quando se perde a oportunidade de capacitar um funcionário.

- Espera: tempo perdido na espera por feedbacks de informações, reuniões, ligações, etc;

- Estratégia: é o valor e tempo perdidos na implantação de processos de curto prazo, os quais não agregam valor a organização, sócios e investidores e clientes;

- Falta de foco: ocorre quando um funcionário perde atenção sob a organização;

- Falta de integração: é o trabalho gasto para transferir informações, dados ou materiais dentro de uma organização mal integrada;

- Fluxo irregular. recursos desperdiçados em materiais ou informações os quais se acumulam entre estações de trabalho e geram desperdícios;

- Informações perdidas: falta de informações chaves para recursos solicitados;

- Irrelevância: trabalho gasto para lidar com informações desnecessárias ou para achar problemas decorrentes delas;

- Tradução: trabalho em alterar dados, formatos e relatórios entre passos dos processos ou de seus funcionários responsáveis.

\section{METODOLOGIA}

A pesquisa visa analisar, a partir das diretrizes do Lean Office presentes na literatura, a gestão de estoques em um elo da cadeia de suprimentos de venda e distribuição de livros. Dessa forma, elaborou-se a Tabela 1 listando-se as principais diretrizes aplicadas ao ramo, e, assim, formulou-se o roteiro da entrevista o qual foi aplicado no CD e posteriormente na Livraria.

Para uma melhor compreensão e preservação das identidades dos entrevistados, foram adotados nomes fictícios para eles. Dessa forma, o respondente do CD recebeu o nome de $\mathrm{R} 1$ e a entrevistada da livraria, R2. E, como foco, só é tratada a parceria entre o CD e a livraria na comercialização de livros didáticos.

Tal roteiro possibilitou a comparação das políticas de estoque em cada organização. Assim, foi possível traçar as características de cada gestão e comparar os impactos que cada uma tem sobre a outra. Dessa forma, a Tabela 1 mostra os itens que possam gerar erros na administração dos estoques e, consequentemente, acarretam prejuízos financeiros nas suas parceiras. 
Tabela 1: Desperdícios constatados

\begin{tabular}{|c|c|c|}
\hline Item & CD & Livraria \\
\hline $\begin{array}{l}\text { Informações } \\
\text { perdidas }\end{array}$ & $\begin{array}{l}\text { Omissão de pedidos; } \\
\text { Falha no armazenamento de dados de } \\
\text { entradas e saídas. }\end{array}$ & Imprecisão na solicitação dos livros \\
\hline \multirow[t]{2}{*}{ Fluxo irregular } & $\begin{array}{l}\text { Demanda por produtos que não constam } \\
\text { em estoque }\end{array}$ & \\
\hline & $\begin{array}{l}\text { Falha na comunicação entre os setores da } \\
\text { empresa; }\end{array}$ & $\begin{array}{l}\text { Falha na comunicação entre os setores da } \\
\text { empresa; }\end{array}$ \\
\hline Falta de integração & $\begin{array}{l}\text { Falta de comunicação com a livraria, gerando } \\
\text { falhas no processamento de pedidos. }\end{array}$ & $\begin{array}{l}\text { Falta de comunicação com o CD, gerando } \\
\text { falhas no processamento de pedidos. }\end{array}$ \\
\hline & $\begin{array}{l}\text { Demora na entrega dos pedidos por erros } \\
\text { de layout, roteirização, furtos, colaboradores }\end{array}$ & $\begin{array}{l}\text { Demora no recebimento dos pedidos por } \\
\text { layout mal elaborado. }\end{array}$ \\
\hline Espera & $\begin{array}{l}\text { sem treinamento adequado e falha na } \\
\text { organização dos materiais nos veículos. }\end{array}$ & \\
\hline Inspeções & $\begin{array}{l}\text { Tempo perdido com inventários } \\
\text { desnecessários. }\end{array}$ & $\begin{array}{l}\text { Tempo perdido com inventários } \\
\text { desnecessários. }\end{array}$ \\
\hline
\end{tabular}

Fonte: Adaptado de Lareau (2002).

Após o levantamento bibliográfico que ensejou a construção das diretrizes da pesquisa (Tabela 1), foram realizadas visitas técnicas às duas empresas - Centro de distribuição e Livraria - aplicando-se uma entrevista semiestruturada aos gestores das empresas estudadas. Os resultados foram comparados em busca da percepção dos dois lados da cadeia em tela.

\section{ESTUDO DE CASO}

\subsection{Resultados}

A partir da coleta de dados no Centro de Distribuição (CD), com base na Tabela 1, obteve-se um panorama de como é encarada a sua administração dos estoques. No que tange à gestão das informações, há um cuidado com o controle das entradas e saídas. Todavia, existem problemas apontados, como o de acumulação de informações desnecessárias, como notas fiscais de até cinco anos atrás, apesar de não ser considerado um problema por R1, no caso desse último, pelo fato da ocupação de espaço não acarretar prejuízos.

Ademais, ele também relatou que já houve casos de perdas de pedido, por falta de registro desses no sistema. A organização utiliza o e-mail para deixarem registradas as solicitações, mas, por falhas humanas, eventualmente os pedidos são esquecidos, apesar de o entrevistado declarar que não ocorre perdas para os clientes.

No que se refere ao fluxo irregular, o entrevistado (R1) explanou que nunca houve vendas de produtos que não estão em estoque e que quando os clientes afirmam que o que foi solicitado chegou de forma 


\section{ISSN - 2447-178X}

errada, eles recolhem e enviam o que se foi solicitado sem haver problemas.

Em relação à espera, há uma série de características importantes, tais como: o centro de distribuição não faz entregas para seus clientes; a solicitação de livros para a matriz é realizada pelos próprios funcionários, que utilizam o Sistema de Informação aliado às suas concepções; R1 também afirmou que, na sua percepção, as entregas dos pedidos poderiam ser mais rápidas e que os funcionários temporários geram gargalos e esperas, uma vez que são pouco ou mal treinados.

Outra preocupação exposta por $\mathrm{R} 1$ diz respeito à organização sempre frequente do layout e limpeza do depósito, organizando os materiais de acordo com a sua importância, com objetivo de deixá-los de fácil acesso no estoque, para não haver gargalos em suas saídas.

Referente às inspeções, foi explicado que há uma atualização de dados rigorosa no sistema dos produtos que entram e saem, além de se produzirem relatórios mensais das variações do estoque. Porém, o entrevistado declarou que mesmo possuindo o Sistema de informação (SI), houve falhas de mal gerenciamento. Por exemplo, há produto que consta no estoque virtual, mas não no físico ou do produto ser registrado no estoque virtual de forma errada, gerando um retrabalho.

Após colher os dados no $C D$, partiu-se para a livraria, tendo em vista às mesmas diretrizes. No que concerne ao tratamento das informações, a livraria também trabalha com um sistema de informação, porém não o utiliza completamente quando solicitam novos livros, fazendo isso por meio de suas próprias percepções, ignorando os mpetodos de previsão agregados. Levando-se em consideração listas escolares e as demandas por livros.

$\mathrm{Na}$ perspectiva do quesito fluxo irregular, a entrevistada (R2) informou que dificilmente há deterioração de livros dentro dos depósitos, loja ou ao longo do caminho da entrega. Apenas há, como exemplo apontado, a devolução de livros com nomes dos clientes.

A livraria possui uma parceria com o $\mathrm{CD}$, a qual se dá quando os livros são reformulados. Dessa forma, o $C D$ os recolhem e a livraria recebe um crédito de compras, no valor dos livros que foram recolhidos.

Segundo o que foi exposto, não há falhas frequentes na comunicação entre setores e colaboradores da empresa. Também não há problemas na comunicação com o $\mathrm{CD}$, que é feita por e-mails ou telefonemas. Porém foi relatado que já houve casos de esquecimento dos pedidos realizados pela livraria por parte do CD.

$\mathrm{Na}$ perspectiva do item espera, há preocupação por parte da livraria em não passar dos prazos estabelecidos para os clientes e diminuir ao máximo os gargalos nos períodos sazonais. Dessa forma, eles adotam medidas, como: contratar mais funcionários nesses períodos, chegando a seis em apenas um balcão e dois motoqueiros exclusivos para entregas; e treinar os funcionários temporários cerca de dois ou três meses antes deles começarem a trabalhar efetivamente.

Quando o que foi solicitado ao CD não está em estoque, a livraria aceita esperar, chegando o prazo a quinze dias para receber os livros, em média. Entretanto foi afirmado que isso não acarreta problemas nas vendas.

No item de controle de inspeções, a colaboradora (R2) informou que eles se preocupam em manter inventários em dia, o que mantém seus estoques atualizados, como também de receber, somente produtos que possuem notas fiscais. Contudo, a mesma também apontou falhas, como a de não haver 


\section{ISSN - 2447-178X}

o número/ tipo de livros em estoque com os registrados nas notas fiscais; e também aludiu que há acumulo de informações desnecessárias, tanto no sistema quanto em espaços físicos, porém afirma que isso não acarreta problemas.

\subsection{DISCUSSÕES}

A partir da coleta de dados no $\mathrm{CD}$ e na livraria e considerando as diretrizes do Lean Office, obteve-se um panorama de como é encarada a administração dos estoques nas empresas em estudo. No que se refere à gestão das informações, os respondentes das duas empresas consideram que há um cuidado adequado com o controle das entradas e saídas de pedidos, no entanto o entrevistado do CD confessa que já houve casos de não separar os pedidos feitos pela livraria por descuido, ocasionando um imprevisto solucionado de modo rápido, mas que em um maior intervalo de tempo pode ocasionar prejuízos.

O principal problema citado pelo $C D$ é gerado por uma falha no registro de livros. Em alguns casos existem livros do tipo "A" no estoque, porém estão registrados como livros " $\mathrm{B}$ ", adversidade que não ocorre na livraria. Em contraponto, esta última afirma existirem situações de haver livros registrados no sistema e não os encontrar no estoque, contudo as duas organizações fazem relatórios semanalmente ou mensalmente do seu estoque já que este varia de acordo com o período sazonal de vendas.

O CD admite que não trabalha com vendas de produtos que não dispõem em estoque, ao contrário da livraria que possui um sistema de "credlivro", o qual entrega o livro ao cliente em um prazo máximo de 30 dias. Contudo, as duas consideram não ser frequente a falta de livros e, caso isso aconteça, é devido a uma grande procura no mercado que não foi prevista.

No ramo de venda de livros, sobretudo os didáticos há o período estacional de vendas em virtude da chegada da etapa de maturação no mercado. Logo, quando a edição atinge seu tempo limite, este é reformulado e, se ainda constar nos estoques das livrarias, o CD recolhe esse material e o envia para sua matriz em São Paulo, gerando um crédito para a livraria pedi-lhes novos livros. Quando se trata de fazer o pedido de livros, a estratégia de fazê-lo fundado de acordo com o que é adotado nas escolas e pela procura dele no mercado é utilizada pelas duas organizações.

Mesmo com a integração dos estoques cada vez mais frequentes nas empresas, as duas que foram estudadas para produção do presente artigo não utilizam desse mecanismo para controlar seus estoques. Acreditam que não seria um meio de supervisão com sucesso aplicada ao negócio. Apesar disso, as empresas consideram que existe uma comunicação eficiente dentro dos seus próprios estabelecimentos, de setor para setor.

Já em relação aos métodos aplicados pelas empresas para reduzir a espera no atendimento, nos períodos de pico de vendas, são semelhantes. Meses antes dessa fase, cada empresa contrata funcionários extras para o atendimento e a entrega. A diferença se encontra no tempo de treinamento oferecido por cada uma. $\mathrm{OCD}$, apesar de perceber que oferece pouco tempo para o treinamento dos funcionários temporários, dá menos tempo que a livraria. Outra maneira que eles buscam para evitar ociosidade no processo é manter todo o seu estoque de livros no balcão, ordenado por séries e matérias, 
controlandoo nível do estoque de forma empírica.

\section{CONCLUSÃO}

O objetivo do estudo buscou analisar um elo de uma cadeia de suprimentos, comparando os impactos da gestão de estoques, com foco no Lean Office, em um Centro de Distribuição (CD) de livros sobre uma livraria.

Dessa forma, a partir da análise das entrevistas realizadas com as organizações, restam claro as dificuldades e erros encontrados nas suas gestões. Apesar da preocupação com o controle das entradas e saídas, ainda há uma falha nos registros dos produtos e isso já ocasionou falhas na realização e recebimento dos pedidos e até cadastros errados.

Além dessas características apontadas, atestou-se que não há uma preocupação em se realizar uma maior aproximação entre fornecedor (CD) e cliente (livraria). Como, por exemplo, é inexistente o mecanismo de integração dos estoques, por desconhecerem que tal ação pode gerar benefícios para as duas empresas estudadas.

Portanto, é lícito aduzir que as duas organizações desconhecem os métodos do Lean Office e os benefícios que ele poder vir a gerar. Também se pode afirmar que a maior parte do controle dos estoques é realizada de forma empírica, não se utilizando de métodos quantitativos em sua maioria.

Ampliando-se a presente pesquisa, sugere-se para trabalhos futuros a realização do estudo de uma cadeia completa, com base nos conceitos do Lean Office, em diferentes áreas comerciais e sem fins lucrativos, contribuindo não só aos pesquisadores, mas com a comunidade acadêmica em geral.

\section{REFERÊNCIAS}

BALLOU, R. H. Gerenciamento da Cadeia de Suprimentos/Logística Empresarial. Tradução de Raul Rubenich. 5 ed. Porto Alegre: Bookman, 2006, 191 p.

CARNEIRO, C. J. M., COSTA, R. S., JARDIM, L. S., VIANA, Á. L., SANTOS, R. Proposta de uso do lean office na redução do tempo de atendimento na análise de projetos das indústrias do polo industrial de Manaus. Revista Espacios, v. 38, n. 19, p. 9, 2017.

CARVALHO, M. C. de, CAMPOS, P. H. F. L., SERRA, C. M. V. Análise do efeito chicote em um elo da cadeia de suprimentos de uma empresa produtora de óleos e gorduras vegetais. Em: ENEGEP, 2015, Fortaleza. P. 2 - 13.

COSTA, T. D., BORGES, I. R., KAERCHER, A. R., FONSECA, G. de B. Políticas para o gerenciamento de estoques: um estudo de caso em uma empresa do ramo metalmecânico de médio porte. In: ENEGEP, 2012, Bento Gonçalves. p. 2 - 10. Disponível em: <http://goo.gl/dUHbDo>. Acesso em: 27 mar. 2016.

COOPER, M. C., LAMBERT, D. M., PAGH, J. D. Supply chain management: more than a new name for logistics. The international journal of logistics management, v. 8, n. 1, p. 1-14, 1997. 


\section{ISSN - 2447-178X}

FERREIRA, M. R. O., MATOS, L. S., MIRANDA, K. S. C, ASSUNÇÃO, M. V.D. Auditoria logística para gerenciamento de estoques em micro e pequenas empresas. Em: ENEGEP, 2015, Fortaleza. P. 1 - 12.

LAREAU, W. Office Kaizen: transforming office operations into a strategic competitive advantage. ASQ Quality Press, 2002.

LUMMUS, R. R., VOKURKA, Robert J. Defining supply chain management: a historical perspective and practical guidelines. Industrial Management \& Data Systems, v. 99, n. 1, p. 11-17, 1999.

MCMANUS, H. Product Development Value Stream Analysis and Mapping Manual (PDVSM). Cambridge: Lean Aerospace Initiative, 2003.

MELO, M. T., NICKEL, S., SALDANHA-DA-GAMA, F. Facility location and supply chain management-A review. European journal of operational research, 196(2), 401-412, 2009.

PELLEGRINI, N. B. S. Análise das operações e relacionamentos entre as empresas com distribuição de bens de conveniência do setor alimentício. 2012. 169 f. Dissertação (Mestrado em Administração) - Universidade Metodista de Piracicaba, Piracicaba. 2012.

PIRES, S. R. I. Gestão da cadeia de suprimentos: conceitos, estratégias, práticas e casos. São Paulo: Atlas, 2004.

SLACK, N., CHAMBERS, S., JOHNSTON, R. Administração da produção. 3 ed. São Paulo: Atlas, 2009. VIANA, João José. Administração de materiais: um enfoque prático. Atlas, 2000.

WOMACK, J. P., JONES, D. T. A mentalidade enxuta nas empresas Lean Thinking: elimine o desperdício e crie riqueza. Elsevier Editora, 2004. 